Impacts of small scale rainfall variability in urban areas: a case study with 1D and 1D/2D hydrological models in a multifractal framework

Auguste Gires ${ }^{1}$, Agathe Giangola-Murzyn ${ }^{1}$, Jean-Baptiste Abbes ${ }^{1}$, Ioulia Tchiguirinskaia $^{1}$, Daniel Schertzer ${ }^{1}$, Shaun Lovejoy ${ }^{2}$

1 U. Paris-Est, Ecole des Ponts ParisTech, LEESU, France,

2 McGill U., Physics dept., Montreal, PQ, Canada

* Corresponding author: Auguste Gires, auguste.gires@leesu.enpc.fr (+33 1641536 48) 


\title{
Impacts of small scale rainfall variability in urban areas: a case study with 1D and 1D/2D hydrological models in a multifractal framework
}

\author{
In this paper the sensitivity to small scale unmeasured rainfall variability (i.e. at \\ scales smaller than $1 \mathrm{~km} * 1 \mathrm{~km} * 5 \mathrm{~min}$ in time, which are usually available with C- \\ band radars) of a 1D/2D model with a $10 \mathrm{~m}$ resolution and a semi-distributed $1 \mathrm{D}$ \\ model of the same $1.47 \mathrm{~km}^{2}$ urban area is analyzed. The $1 \mathrm{D} / 2 \mathrm{D}$ model is the open \\ source numerical platform Multi-Hydro, which couples (open source) distributed \\ models of involved hydrological/hydraulic processes. The methodology \\ implemented to evaluate the uncertainties consists in generating an ensemble of \\ realistic rainfall fields downscaled to a resolution of $12.3 \mathrm{~m}$ in space and $18.75 \mathrm{~s}$ \\ in time with the help of a stochastic universal multifractal model. The \\ corresponding ensemble of hydrographs is then simulated. It appears that the \\ uncertainty is significant and that Multi-Hydro unveils much more uncertainty \\ than the simpler 1D model. This points out a need to develop high resolution \\ distributed modelling in urban areas.
}

Keywords: Rainfall variability, 1D/2D modelling, multifractals, space-time downscaling

\section{Introduction}

Rainfall variability has a significant impact on river discharges (see Singh, 1997 for a review). This impact is enhanced in urban areas where the response times of catchments are shorter and the coefficients of imperviousness are larger meaning that a greater fraction of rainfall is immediately active (Aronica and Cannarozzo, 2000; Segond et al., 2007). The under-representation of rainfall variability in input data of models affects the confidence one should have in its predictions. A better understanding of rainfall variability in urban areas and its impact on simulated flow is needed both theoretically and operationally. Indeed Real Time Control (RTC, see Schütze et al., 2004 for a review 
of its rapid development over the last decades) of sewer networks, which aims at reducing urban flooding and pollution, relies on the use of such models.

In recent papers Gires et al. (2012a, 2012b) quantified the impact of small scale unmeasured rainfall variability (i.e. at scales smaller than the C-band radar resolution of $1 \mathrm{~km} \times 1 \mathrm{~km} \times 5 \mathrm{~min}$, which is usually provided by national meteorological services of Western Europe countries) on urban discharges simulated with the help of semidistributed urban hydrological / hydraulic 1D models. Two urban areas were studied: a 3400 ha one located near Paris and a 900 ha one located in the North of London. The methodology implemented relied on the generation and analysis of realistic ensembles: (i) generation of an ensemble of realistic rainfall fields through a stochastic multifractal downscaling of the radar data, (ii) Simulation of the corresponding ensemble of hydrographs with a semi-distributed 1D model, (iii) Quantification of the variability among these ensembles. A limitation of these works was that the size of the subcatchments (roughly 17 ha on average), which are considered as homogenous objects, did not enable to fully grasp the actual rainfall spatial variability. In this paper we implement the same methodology on a portion of size 144 ha of the previous Paris area case study (see Figure 1). Two types of models are used: the same semi-distributed operational one and a 1D/2D fully distributed one called Multi-Hydro. It is a numerical platform currently being developed at Ecole des Ponts ParisTech and validated in the framework of FP 7 SMARTeST European Project (v1 El Tabach et al., 2009; v2 Giangola-Murzin et al., 2012). The aim of the paper is mainly to develop a methodology to take into account small scale unmeasured rainfall variability, and test how two different models quantify the associated uncertainty on three rainfall events. 
The rainfall event and data are described in section 2.1. Section 2.2 briefly presents of Multi-Hydro. The 144 ha studied urban area denoted Kodak catchment and its representation with the two models is presented in section 2.3. Section 2.4 describes the implemented methodology. Results are discussed in section 3.

\section{Data and methods}

\section{Rainfall data}

The three rainfall events studied in this paper occurred over the Paris area on February $9^{\text {th }}, 2009$, August $15^{\text {th }} 2010$ and December $15^{\text {th }}$ 2011. In the following they will simply be denoted 2009, 2010 and 2011 event. The rainfall data is the Météo-France radar mosaic whose resolution is $1 \mathrm{~km}$ in space and $5 \mathrm{~min}$ in time. The rainfall rate $R$ is basically computed from the radar reflectivity $Z$ with the help of a standard $Z=a R^{b}$ relationship with $a=200$ and $b=1.6$ ( $Z$ in $\mathrm{mm}^{6} \cdot \mathrm{m}^{-3}$ and $R$ in $\mathrm{mm} \cdot \mathrm{h}^{-1}$ ). Details about the additional corrections which are implemented can be found in Tabary (2007). The studied catchment is located at approximately $45 \mathrm{~km}$ of the C-band radar of Trappes (West of Paris) meaning that the rainfall estimates are still reliable (Tabary et al, 2007). The temporal evolution of the average rain rate over the Kodak catchment for the three events are displayed Fig. 2. The total rainfall depth for the 2009, 2010 and 2011 event is respectively $8.3 \mathrm{~mm}, 56.5 \mathrm{~mm}$ and $23.8 \mathrm{~mm}$ for durations of approximately $6 \mathrm{~h}, 30 \mathrm{~h}$

and $12 \mathrm{~h}$. These events are heavy ones especially the last two, but over a duration of 1 or 4 hour, none has a return period greater than 1 year (data from a rain gauge located in the Paris area that was available to the authors was used to confirm that).

\section{Short presentation of Multi-Hydro}

There is a growing interest for taking into account more precisely the interactions 
between surface and sewer flows in the field of urban hydrology (Hsu et al. 2000; Jankowsky 2011; Leandro et al., 2009; Maksimovic et al., 2009; Rodriguez et al., 2008). In that context, Multi-hydro is a numerical platform currently under development that makes interact several open source software packages each of them representing a portion of the water cycle in urban environment. The second version that is used in this paper consists in an interactive coupling between a 2D model representing surface runoff and infiltration (TREX, Two dimensional Runoff, Erosion and eXport model, Velleux et al., 2011) and a 1D model of sewer networks (SWMM, Storm Water Management Model, Rossman, 2007). Only the hydraulic part of SWMM is used to model water flow in pipes, and not the hydrologic one. The main input data is a precise description of the sewer network, the topography, and the land use distribution. In this case study six different classes of land use are used (wood, grass, water, roads, building and gullies), each being fully characterized by its hydraulic conductivity $(\mathrm{m} / \mathrm{s})$, capillary suction (m), moisture deficit (no unit, ranging from 0 to 1 ), Manning coefficient ( $\mathrm{s} . \mathrm{m}^{-1 / 3}$ ) and depth of interception $(\mathrm{mm})$. With regards to the land use distribution only one class can be affected to each pixel. Therefore, as a pixel usually contains several types of land use, an order of priority must be set to determine the land use of a pixel actually containing several ones (in the vector GIS data). The order set here is gully, road, buildings, water, wood and grass. The influence of this feature will be discussed in the following. Concerning the topography the digital terrain model used was provided by the Institut National de l'Information Géographique et Forestière (http://professionnels.ign.fr/), and does not take into account anthropogenic elevation modification (buildings are removed from the raw data coming from field measurements). The elevation used in Multi-Hydro is an interpolation of this data whose initial spatial resolution is $25 \mathrm{~m}$ with a vertical resolution of $1 \mathrm{~m}$. As a 
consequence, the raw elevation of the road pixels is decreased by $15 \mathrm{~cm}$ and the building pixels one is increased by $5 \mathrm{~m}$ to prevent water from running through these pixels. The rainfall collected by the building pixels is directly routed to the nearest gully. The interactions between the stormwater sewer system and surface flow are handled through the gullies where water can circulate in both ways, i.e. from surface to sewer in standard situation, and the other way in case of sewer overload. More details about Multi-Hydro can be found in Giangola-Murzyn et al. (2012). The data is formatted for Multi-Hydro from commonly available GIS data with the help of an inhouse developed tool called MH AssimTool (Richard et al., 2012). This enables to (rather) easily implement the model on a new catchment.

\section{Studied catchments and their representation with the help of two models}

The catchment (denoted Kodak catchment after) which is mainly studied i.e. where the impact of small scale rainfall variability is tested, is a roughly $1.4-1.5 \mathrm{~km}^{2}$ urban area located in the city of Sevran (Seine-Saint-Denis county, North-East of Paris). The area is rather flat with an elevation difference of only $11 \mathrm{~m}$ between the highest point and the

outlet. There is a separate sewer system in the area, and the storm water drainage system regularly overflows, hence a project to build a storm water storage basin to limit it. The basin will also enable to reduce water transfer during heavy rainfall to the downstream area just north of it which suffers frequent pluvial flooding. There is a flow gauge in the conduit above the park which corresponds to a former Kodak factory (see Fig. 1). It drains all the East part of the catchment (about 2/3 of the total area). The operators of the gauge told us that the accuracy of the flow measured by this gauge is not very good because it is located just downstream a screen. It was actually initially installed to study the flow features just downstream this screen. There is unfortunately no data available 
to assess the uncertainty associated with this measurement. Figure 3.b displays the land use distribution for pixels of size $10 \mathrm{~m}$ x $10 \mathrm{~m}$ for which most of the study will be carried out, along with the storm water drainage system (waste water sewers are not modelled in this study).

The Direction Eau et Assainissement of Seine-Saint-Denis (DEA 93, the local authority in charge of urban drainage) calibrated and runs operationally the semidistributed 1D model Canoe (Allison et al., 2005) on this area. In Canoe the hydrologic response of each sub-catchment is modelled with the help of a lumped model (a linear reservoir) and the flow in the pipes is modelled with the help of a numerical solution of Saint-Venant equations. The studied area (see Figure 3.d) is divided into 16 subcatchments whose size is ranging from 4 to 14.5 ha. The total area studied with the $1 \mathrm{D}$ model is $1.39 \mathrm{~km}^{2}$ (the difference with Multi-Hydro comes from side effects), and the average coefficient of imperviousness is equal to $53 \%$.

Another catchment called "Loup catchment” is studied in this paper to validate the Multi-Hydro model. It is a $0.5 \mathrm{~km}^{2}$ area also located in Seine-Saint-Denis County few kilometres North-East of the Kodak catchment. It is mainly an industrial area with a small portion of housing estate. The area is rather flat with an elevation difference of only $12.5 \mathrm{~m}$ between the highest point and the outlet, and drained by a separate sewer network. We only model the storm water drainage network. Figure 4 displays its representation in Multi-Hydro with pixels of size $10 \mathrm{~m}$ x $10 \mathrm{~m}$, and the storm water sewer network. The outlet of the catchment is the roundabout visible in the South-West portion of the catchment. It is actually a storm water storage basin managed by the DEA 93, which receives water only from this catchment. At the beginning of an event, the outlet gate of the basin is closed, which means that the water volume contained in the basin corresponds to the one generated by the Loup catchment. There is a water level 
gauge with a precision of roughly $1 \mathrm{~cm}$ monitoring in real time the basin. This height coupled with a precise geometrical description of the basin enables to plot the temporal evolution of the volume observed in the basin and compare it with the cumulated flow simulated with the help of Multi-Hydro at the outlet of the Loup catchment.

\section{Methodology}

In order to quantify the uncertainty associated with small scale unmeasured rainfall variability, the following methodology is implemented for each event: (i) An ensemble of 100 realistic downscaled rainfall fields with a resolution of $12.3 \mathrm{~m}$ in space and 18.75 $\mathrm{s}$ in time is generated. For the semi-distributed model, given the size of the homogeneous sub-catchments, the rainfall was only downscaled only to $111 \mathrm{~m}$ in space and 1.25 min in time. (ii) The corresponding ensemble of hydrographs is then simulated for each model. (iii) The variability among the hydrographs is characterized with the help of the envelop curves $Q_{0.1}, Q_{0.25} Q_{0.75}$ and $Q_{0.9}$, which are respectively made of the 10, 25, 75 and $90 \%$ quantiles (in $\mathrm{m}^{3} / \mathrm{s}$ ) estimated for each time step. Finally we compute for the peak flow a pseudo coefficient of variation defined as:

$$
C V^{\prime}=\frac{Q_{0.9}\left(t_{P F, \text { radar }}\right)-Q_{0.1}\left(t_{P F, \text { radar }}\right)}{2 * P F_{\text {radar }}}
$$

where $\boldsymbol{P} F_{\text {radar }}$ is the peak flow simulated with the raw radar data and $\boldsymbol{t}_{P F \text {, radar }}$ is its time of occurrence. In this paper, for flow $C V^{\prime}$ is discussed only for $\boldsymbol{t}_{P F, \text { radar }}$, and it corresponds to the time step for which it the greatest. This is a quantitative indicator of the uncertainty associated with small scale rainfall variability for the peak flow which is of prime importance for urban hydrologists. 
The rainfall input downscaling technique relies on the framework of Universal Multifractals (Schertzer and Lovejoy, 1987), which has been extensively used (Schertzer and Lovejoy, 2011 for a recent reviews; de Lima and de Lima, 2009, and Verrier et al., 2010, for applications in hydrology) to analyse and simulate geophysical fields extremely variable over wide ranges of scales. In this framework it is assumed that rainfall is generated through a space-time multiplicative cascade process characterized with the help of only two parameters; $C_{1}$ the mean intermittency (which measures the average sparseness of the field) and $\alpha$ the multifractality index (which measures the variability of the intermittency when considering intensities slightly different from the average field). The downscaling implemented in this paper simply consists in stochastically continuing the cascade process whose features are assessed over the available range of scales. No data on these events was available to confirm the validity of the multifractal framework down to scale of $12.3 \mathrm{~m}$ and $18.75 \mathrm{~s}$. However Mandapaka et al. (2009) showed with the help of Lidar data that rainfall exhibited a scaling behaviour down to $1 \mathrm{~m}$ in space and $1 \mathrm{~s}$ in time. Discrete cascades are used. The UM parameters used here are $\alpha=1.8$ and $C_{1}=0.1$ which corresponds to the ones usually found focusing the analysis on the rainy portion of the rainfall field (de Montera et al, 2009; Mandapaka et al., 2009; Verrier et al., 2010, Gires et al., 2013). More details on the downscaling process can be found in Gires et al. 2012b. A validation of the downscaling model with the help of two dense networks of 16 disdrometers or rain gauges deployed over a $1 \mathrm{~km}^{2}$ area in respectively Switzerland and United Kingdom is suggested in Gires et al. (2014). More details on the simulation of Universal Multifractal fields can be found in Pecknold et al. 1993 and Lovejoy and Schertzer 2010. 


\section{Results and discussion}

\section{Models resolution and validation}

Before discussing the issue of the validation of the models, it is required to address the question of the resolution of Multi-Hydro, i.e. the size of its pixels. Indeed as mentioned before, Multi-Hydro is developed so that a single land use class is affected to each pixel, and therefore an order of priority is set to determine the class of a pixel. An illustration of this feature is given Fig. 3 which displays the land use distribution obtained with pixels of various sizes. Stricking differences are visible. For example the gardens attending the houses are almost not visible with pixels of size $20 \mathrm{~m}$ x $20 \mathrm{~m}$ whereas they are with pixels of size $1 \mathrm{~m}$ x $1 \mathrm{~m}$. These differences result in hydrological consequences. An illustration is the percentage of impervious area (gully, road and building pixels), which reflects the portion of storm water rapidly active. It is equal to $87,83,77,63,53,47,40 \%$ respectively for pixels of size $20,15,10,5,3,2,1 \mathrm{~m}$. The size of the modelled area ranges from $1.49 \mathrm{~km}^{2}$ with a 20 m pixels to $1.42 \mathrm{~km}^{2}$ with $1 \mathrm{~m}$ pixels. It is interesting to note that such behaviour is rather standard of a fractal set. Such set is characterized by a fractal dimension $D_{\text {F }}$ defined with the help of the following equation:

$$
N_{\lambda} \approx \lambda^{D_{F}}
$$

Where $N_{\lambda}$ is the number of boxes of size $l$ needed to completely cover it and $\lambda$ is the resolution ( $\lambda=L / l$, with $L$ the outer scale of the set). Here $N_{\lambda}$ was computed from the impervious pixels of a $1024 \mathrm{~m}$ x $1024 \mathrm{~m}$ area of the $1 \mathrm{~m}$ grid (Figure 3.a). The straight line ( $R^{2}$ greater than 0.99$)$ reflects that it is a fractal set, and the slope equal to 1.85 corresponds to the fractal dimension (Fig. 5). The fact that the geometrical set of impervious areas exhibits a fractal behaviour suggests that such tool should be used 
more frequently in order to first characterize urban environment and then model it. This is nevertheless not the scope of this paper, which focuses on the rainfall input, to investigate more in-depth this issue.

This feature of one single land use class per pixel is a limit of Multi-Hydro, but also a strength since this simple rule enables to develop an automatic process to generate input data from available GIS data which make the model easily transportable. The selected resolution of Multi-Hydro results from a trade off between the computation time (which increases non-linearly with decreasing pixel size), the quality of the available land use distribution (a non - obvious issue at high resolution in urban areas!) and the desired accuracy according to the application. In this paper Multi-Hydro is used with pixels of size $10 \mathrm{~m}$ x $10 \mathrm{~m}$ and $5 \mathrm{~m}$ x $5 \mathrm{~m}$ for the Kodak catchment, and only $10 \mathrm{~m}$ x $10 \mathrm{~m}$ for the Loup catchment. Multi-Hydro is implemented without any calibration, i.e. standard values for the 5 parameters describing a land use class are used (GiangolaMurzyn et al. 2012). For the Kodak catchment the resolution of Canoe corresponds roughly to pixels of size $300 \mathrm{~m}$ (obtained simply by taking the square root of the catchment area divided by the number of sub-catchments). The average coefficient of imperviousness is equal to $53 \%$ which roughly corresponds to the value found with pixels of size $3 \mathrm{~m}$ in Multi-Hydro.

Figure 6 displays the temporal evolution of the flow simulated with the different models (Multi-Hydro $10 \mathrm{~m}$ and $5 \mathrm{~m}$, and Canoe) and the flow measurements (see Figure 1 for the location of the flow gauge) for the Kodak catchment and the 2009 event (the only one for which flow measurements are available). This rainfall event did not generate any storm water sewer overflow. The curves for the different models exhibit rather comparable patterns. The differences in terms of numerical values are essentially due to 
the variations of the percentage of impervious area. The time of peak flow is similar for all these curves with less than 5 min shift. Concerning the comparison with the measurements, the Nash-Sutcliffe coefficient is equal to 0.40 for $\mathrm{MH} 10 \mathrm{~m}, 0.68$ for $\mathrm{MH}$ $5 \mathrm{~m}$, and 0.78 for Canoe. The three models react too quickly at the beginning of the rainfall which is likely to be due to a misrepresentation of the initial losses. The three models also miss the first measured peak (slightly before 5h of simulations). There is no clear explanation for this, but it could be due to errors in the rainfall measurement (possible for this event, see comments on next paragraph) or the flow measurement which are known to be not very accurate here. Anyway more events should be tested to properly validate these models.

Multi-Hydro was also tested with pixels of size $10 \mathrm{~m}$ x $10 \mathrm{~m}$ on the Loup catchment (see Abbes, 2013 for more an extensive study). With this resolution, the percentage of impervious areas is of roughly $90 \%$. No additional calibration was done on MultiHydro and the same parameter set as for the Kodak catchment was used. Figure 7 displays the volume measured in the storage tank, and the simulated one for the three events with raw radar data and also with the data (considered homogenous over the catchment) from a rain gauge located $1 \mathrm{~km}$ away from the catchment. The simulated volume is the cumulative flow at the outlet. For the 2011 event, the agreement is good. The 2010 event lasted $30 \mathrm{~h}$, hence water was released from the storage tank during that time, which is why three portions had to be selected to compare measurements and simulations. During the first portion, Multi-hydro with both rainfall inputs (radar and rain gauge) overestimates observed volume. During the second one, measurements are in between simulations with radar and rain gauge data. For the third one Multi-Hydro tends to slightly overestimate volume. Except for the first portion, which might reflect issues in the handling of initial loss and watering of surfaces, the agreement between 
simulations and observations is good. For the 2009 event discrepancies between radar and rain gauge measurements are the greatest and the measurements (until water is released from the tank after $8 \mathrm{~h}$ ) are between the two simulations. This suggests that there might be some issues with regards to the rainfall estimation for the 2009 event which might explain partially the discrepancies of Fig. 6 .

The aim of the paper is not to reach the perfect model, but only to have enough confidence in the models so that it makes sense to analyse their sensitivity to the rainfall input resolution. The results of the previous paragraphs show that the models are roughly consistent and that it is therefore legitimate to use them for the purpose of the paper.

\section{Uncertainty associated with small scale rainfall variability for various rainfall events and the Multi-Hydro model}

Figure 8 displays the flow simulated with raw radar data $\left(Q_{\text {radar }}\right)$ and the uncertainty intervals $\left(Q_{0.1}, Q_{0.25} Q_{0.75}\right.$ and $\left.Q_{0.9}\right)$ for five conduits obtained for the 2009 event with Multi-Hydro $10 \mathrm{~m}$. The rainfall was downscaled from an initial resolution of $1 \mathrm{~km}$ in space $5 \mathrm{~min}$ in time to respectively $12.3 \mathrm{~m}$ and $18.75 \mathrm{~s}$. The analysis was performed with pixels of size $10 \mathrm{~m}$ x $10 \mathrm{~m}$ even though the simulated flow might be less accurate than with smaller pixels like $5 \mathrm{~m} \times 5 \mathrm{~m}$ because the computation time for each sample is much smaller (roughly $1 \mathrm{~h}$ versus $4 \mathrm{~h}$ on standard laptop). Before going on, it should be mentioned that the observed differences between the hydrographs are not due to variations in the total rainfall amount, but to variations in the spatio-temporal distribution of rainfall. Indeed for the 2009 event the raw radar total rainfall amount is of $8.2 \mathrm{~mm}$, whereas it is of $8.3 \mathrm{~mm}$ on average with a ratio of the difference between the 
$95 \%$ and 5\% quantile and twice the radar total volume equal to 3.4\% (this figure defined on the same principle as the pseudo coefficient of variation $C V$ ' quantifies the variability among the ensemble) for the generated downscaled rainfall fields. For the 2010 event the corresponding values are respectively $56.5 \mathrm{~mm}, 56.5 \mathrm{~mm}$, and 1.6\%. For the 2011 event the corresponding values are respectively $23.8 \mathrm{~mm}, 23.9 \mathrm{~mm}$ and 3.5\%. Theses disparities are much smaller than the ones observed on the simulated discharges even at the outlet (the smallest computed $C V^{\prime}$ is equal to $15 \%$ ). Figure 8 enables to analyse the uncertainty according to the position (i.e. upstream or downstream) of the conduit in the sewer network. As expected the uncertainty increases with upstream conduits. For the February event the computed $C V^{\prime}$ ranges from $15 \%$ for the outlet to $38 \%$ for the most upstream selected conduit. These values are rather elevated, and suggest that a better rainfall input would result in a significant decrease on the uncertainty of the simulated flow. It means that a better rainfall input would help local authorities to better cope with real time management of storm water sewer flooding. Moreover these levels of uncertainties are observed for a moderate rainfall event, which was not necessarily expected. It suggests that higher resolution rainfall would also be needed to improve real time management of water quality.

With regards to the other events, Figure 9 displays the flow simulated with raw radar data $\left(Q_{\text {radar }}\right)$ and the uncertainty intervals $\left(Q_{0.1}, Q_{0.25} Q_{0.75}\right.$ and $\left.Q_{0.9}\right)$ at the outlet for the three selected events. For the 2010 event $C V^{\prime}$ ranges from $21 \%$ at the outlet to $61 \%$ for the most upstream selected conduit (same as in Fig. 8). The values are respectively $18 \%$ and $43 \%$ for the 2011 event. These results are qualitatively similar to the ones obtained for the 2009 event which confirms the conclusions of the previous paragraph. It even appears that the uncertainty associated with small scale rainfall variability tends to be greater for heavier events. 


\section{Comparison of uncertainty computed by the two models}

The flow and its uncertainty simulated with the help of the 1D semi-distributed model at the outlet of the Kodak catchment for the 2009 event is visible Fig. 9.(b). We remind that for the 1D semi-distributed model the rainfall was only downscaled to a resolution of $111 \mathrm{~m}$ in space and $1.25 \mathrm{~min}$ in time and not to respectively $12.3 \mathrm{~m}$ and $18.75 \mathrm{~s}$ as for Multi-Hydro, because the sizes of the sub-catchments (ranging from 4 to 14.5 ha) are already much greater than the size of the pixels of the downscaled rainfall field (1.2 ha). It appears that the uncertainty intervals are much larger with Multi-Hydro than for the 1D model, and this during the whole event and not only the peak flow. This is confirmed by $C V$ ' which is equal to $15 \%$ for the Multi-Hydro $10 \mathrm{~m}$ and to $8 \%$ for the semi-distributed model. It means that such $1 \mathrm{D}$ model is not able to fully take into account the small scale rainfall variability which has been shown to have a significant impact on the simulated flow. It would be interesting to carry out further investigations on $1 \mathrm{D}$ models by testing this methodology for configurations with sub-catchments much smaller (1 ha or less) than the ones of this paper. To actually benefit from the higher resolution rainfall data which is becoming increasingly available in urban areas, there is a need to develop the use of fully distributed model.

\section{Sensitivity of the results to the UM parameters}

In this paper, the same UM parameters $\left(\alpha=1.8, C_{1}=0.1\right)$ have been used for the three events. They correspond to estimates commonly obtained in the literature when focusing the analysis on the rainy portions of the rainfall fields. In this section, we suggest to test the sensitivity of the results to the values of the UM parameters. To achieve this, the same methodology has been implemented for the 2011 event with 
various UM parameters sets. Results are summarized in Table 1. The value of the maximum probable singularity $\gamma_{\mathrm{s}}$ for each parameter set was added. It is a scale invariant estimate of the maximum probable value observable on a unique sample of the phenomenon, and has commonly been used to assess the extremes in the multifractal framework (Hubert et al. 1993, Douglas and Barros 2003, Royer et al. 2008, Gires et al. 2011a).

It appears that the values of the UM parameters have indeed an influence on the computed uncertainty. For example $C V$ ' for the outlet is almost twice decreased when $C_{1}=0.05$ rather than $C_{1}=0.1$ while $\alpha$ is kept equal to 1.8 . One can note that the uncertainty are lower for $\alpha=1.8 C_{1}=0.05$ which corresponds to $\gamma_{\mathrm{s}}=0.36$ than for $\alpha=0.6$ $C_{1}=0.1$ which corresponds to $\gamma_{\mathrm{s}}=0.22$. This result is not expected if only the notion of maximum singularity is used to assess the extremes of the rainfall fields. It simply means both UM parameters are needed to properly characterize the rainfall field and assess the uncertainty associated with small scale rainfall variability. From Table 1, it can be seen that $C_{1}$ has a stronger influence than $\alpha$ on the estimated uncertainty, suggesting that efforts should be focused on its correct estimation.

\section{Conclusion}

Universal multifractals are used to quantify the uncertainty associated with small scale unmeasured (i.e. occurring at scales smaller than $1 \mathrm{~km}$ in space and 5 min in time) rainfall variability on the outputs of Multi-Hydro, a newly developed fully distributed urban hydrologic/hydraulic numerical platform, and a standard semi-distributed 1D model implemented on the same $1.44 \mathrm{~km}^{2}$ urban area located in Sevran, near Paris (France). Three rainfall events with return periods smaller than 1 year for durations of 1 
$\mathrm{h}$ and $4 \mathrm{~h}$ are tested. First the models are roughly validated on both the main case study and an additional $0.5 \mathrm{~km}^{2}$ urban catchment for which more measurements were available. Then the methodology basically consists in generating an ensemble of realistic downscaled rainfall fields and simulating the corresponding ensemble of hydrographs. This enables to quantify the uncertainty. It appears that for the three rainfall events the uncertainty is rather elevated and cannot be neglected. For example CV' ranges between 15 and $21 \%$ at the outlet and between 37 and $61 \%$ for upstream conduits according to the event. Furthermore the uncertainty computed with the help of the fully distributed Multi-Hydro model is much greater than the one obtained with the 1D semi-distributed model, which means that fully distributed models would be needed to fully benefit from improved rainfall data. The sensitivity of the results to the two parameters used to downscale the rainfall field was tested and showed that a special care should be dedicated to estimating them for applications. In this paper, only the sensitivity to rainfall resolution was tested. More generally similar work should be carried out on other common input fields such as the land use distribution, or the soil properties (especially the infiltration capacities). If obtained conclusions are similar, this would confirm that small scale phenomenon should to be taken into account much more carefully in urban hydrology. This points out that in terms of modelling the use of fully distributed models should be developed especially for applications dedicated RTC of sewer networks. The use of the notion of fractal dimension to characterize some features of the inputs of the model also suggests that the implementation of such tools, which are rather common in geophysics, should be developed in urban hydrology. In terms of rainfall, there is a need for higher resolution data in urban areas. To achieve this, the use of X-band radars which provide hectometric resolution would be highly beneficial. Further investigations with heavier rainfall events that generate urban pluvial flooding 
should also be performed to confirm this need for high resolution modelling.

Acknowledgements,

The authors acknowledge Julien Richard (LEESU) for his help in facilitating and reworking the terrain and sewer network data. The authors acknowledge Météo-France for providing the radar rainfall estimates in an easily exploitable format, and especially Pierre Tabary and Valérie Vogt, and the “Direction Eau et Assainissement” of SeineSaint-Denis for providing the 1D calibrated hydrological-hydraulic model of the Kodak catchment, flow measurements and helpful comments on the results. The authors greatly acknowledge partial financial support form the Chair "Hydrology for Resilient Cities" (sponsored by Veolia) of Ecole des Ponts ParisTech, EU FP7 SMARTesT project, EU INTERREG RainGain Project (www.raingain.eu), and EU Climate KIC Blue Green Dream (www.bgd.org.uk)

References:

Abbes, J.B., 2013. Hydrological modelling of the Loup catchment, MSc Intership Thesis, Ecole des Ponts ParisTech, 74 p.

Allison, INSA Lyon, SOGREAH Consultants, www.canoe-hydro.com, 2005. Manuel d'utilisation de Canoe.

Aronica, G. and Cannarozzo, M., 2000. Studying the hydrological response of urban catchments using a semi-distributed linear non-linear model. J. Hydrol., 238, 3543.

El Tabach, E., Tchiguirinskaia, I., Mahmood, O. and Schertzer, D, 2009. Multi-Hydro: a spatially distributed numerical model to assess and manage runoff processes in peri-urban watersheds. Proceedings Final conference of the COST Action C22 Urban Flood Management, Paris 26/27.11.2009, France.

Giangola-Murzyn, A., Gires, A., Hoang, C.T., Tchiguirinskaia, I. and Schertzer, D., 2012. Multi-Hydro: physically based modelling to assess flood resilience across scales, case studies in Paris region. Proceedings of $10^{\text {th }}$ Urban Dranaige conference, Belgrade 3-7 Sept. 2012, Serbia.

Gires, A.., Onof, C., Maksimovic, C., Schertzer, D., Tchiguirinskaia, I. and Simoes, N., 2012a. Quantifying the impact of small scale unmeasured rainfall variability on urban hydrology through multifractal downscaling: a case study. J. Hydrol. 442443, p 117-128. 
Gires, A., Tchiguirinskaia, I., Schertzer, D. and Lovejoy, S., 2012b. Multifractal analysis of an urban hydrological model on a Seine-Saint-Denis study case. Urban Water Journal, 10 (3), 195-208.

Gires, A., Tchiguirinskaia, I., Schertzer, D. and Lovejoy, S., 2013. Development and analysis of a simple model to represent the zero rainfall in a universal multifractal framework. Nonlinear Processes in Geophysics, 20, 343-356.

Gires, A., Tchiguirinskaia, I., Schertzer, D., Schellart, A., Berne, A., Lovejoy, S., 2014. Influence of small scale rainfall variability on standard comparison tools between radar and rain gauge data. Atmospheric Research, 138(0), 125-138.

Hsu, M.H., Chen, S.H. and Chang, T.J., 2000. Inundation simulation for urban drainage basin with storm sewer system. $J$ hydrol, 234, 27-31.

Jankowfsky, S., 2011. Understanding and modelling of hydrological processes in small peri-urban catchments using an object-oriented and modular distributed approach. Application to the Chaudanne and Mercier sub-catchments (Yzeron catchment, France). PhD Thesis., Lyon, France

de Lima, M.I.P. and de Lima, J., 2009. Investigating the multifractality of point precipitation in the Madeira archipelago. Nonlinear Processes in Geophysics, 16(2), 299-311.

de Montera, L., Barthes, L., Mallet, C. and Gole, P., 2009. The Effect of Rain-No Rain Intermittency on the Estimation of the Universal Multifractals Model Parameters. Journal of Hydrometeorology, 10(2): 493-506.

Leandro, J., Chen, A., Djordjević, S., and Savić, D., 2009. Comparison of 1D/1D and 1D/2D Coupled (Sewer/Surface) Hydraulic Models for Urban Flood Simulation. J. Hydraul. Eng., 135(6), 495-504.

Lovejoy, S. and Schertzer, D., 2010. On the simulation of continuous in scale universal multifractals, part I : Spatially continuous processes. Computers \& Geosciences, 36(11), 1393-1403.

Maksimović, Č., Prodanović, D., Boonya-aroonnet, S., Leitão, J.P., Djordjević, S. and Allitt, R., 2009. Overland flow and pathway analysis for modelling of urban pluvial flooding. Journal of Hydraulic Research, 47 (4), 512-523

Mandapaka, P.V., Lewandowski, P., Eichinger, W.E. and Krajewski, W.F., 2009. Multiscaling analysis of high resolution space-time lidar-rainfall. Nonlinear Processes in Geophysics, 16(5): 579-586.

Pecknold, S., Lovejoy, S., Schertzer, D., Hooge, C. and Malouin, J.F., 1993. The simulation of universal multifractals. In: Cellular Automata: Prospects in astrophysical applications, J.M. Perdang and A. Lejeune (Eds), World Scientific, pp 228-267. 
Richard, J., Tchiguirinskaia, I., and Schertzer, D., 2012. GIS data Assimilation interface for distributed hydrological models. Proceedings Hydro-Informatics Conference, Hamburg, 14-18 July 2012, Germany, 2012.

Rodriguez, F., Andrieu, H. and Morena, F., 2008. A distributed hydrological model for urbanized areas - model development and application to case studies. J Hydrol., 351, 268-287

Rossman, L.A., 2010. Storm Water Management Model, User’s Manual. Version 5.0.

U.S. Environmental Protection Agency, EPA/600/R-05/040.

Schertzer, D. and Lovejoy, S., 1987. Physical modelling and analysis of rain and clouds by anisotropic scaling and multiplicative processes. J. Geophys. Res., 92(D8), 9693-9714.

Schertzer, D. and Lovejoy, S., 2011. Multifractals, Generalized Scale Invariance and Complexity in Geophysics. International Journal of Bifurcation and Chaos, 21(12): 3417-3456.

Schüetze, M., Campisano, A., Colas, H., Schilling, W. and Vanrollegheme, P.A., 2004. Real time control of urban wastewater systems-where do we stand today? $J$. Hydrol, 299, 335-348.

Segond, M.L., Wheater, H.S., Onof, C., 2007. The significance of small-scale spatial rainfall variability on runoff modelin. J. Hydrol., 173, 309-326.

Singh, V.P., 1997. Effect of spatial and temporal variability in rainfall and watershed characteristics on stream flow hydrograph. Hydrol. Process., 11, 1649-1669. Tabary, P., 2007. The new French operational radar rainfall product. Part I:

Methodology. Wea. Forecasting, 22, 393-408.

Tabary, P., Desplats, J., Do Khac, K., Eideliman, F., Gueguen, C., Heinrich, J. C., 2007.

The new French operational radar rainfall product. Part II: Validation. Weather and Forecasting, 22(3), 409-427.

Velleux, M.L., England, J.F. and Julien, P.Y., 2011. TREX Watershed Modelling

Framework User's Manual: Model Theory and Description. Department of civil engineering, Colorado State University, Fort Collins, January, 106p.

Verrier, S., de Montera, L., Barthes, L. and Mallet, C., 2010. Multifractal analysis of African monsoon rain fields, taking into account the zero rain-rate problem. $J$. Hydrol, 389(1-2), 111-120. 
Table 1: Values of computed $C V$ ' for three links (the links are the two extreme ones and the middle one that are selected for Fig. 8) for various UM parameters set.

\begin{tabular}{|l|l|l|l|l|}
\hline & $\alpha=1.8 ; C_{1}=0.1$ & $\alpha=1.8 ; C_{1}=0.05$ & $\alpha=1.4 ; C_{1}=0.1$ & $\alpha=0.6 ; C_{1}=0.1$ \\
& $\left(\gamma_{\mathrm{s}}=0.50\right)$ & $\left(\gamma_{\mathrm{s}}=0.36\right)$ & $\left(\gamma_{\mathrm{s}}=0.43\right)$ & $\left(\gamma_{\mathrm{s}}=0.22\right)$ \\
\hline $\begin{array}{l}\text { Up-stream } \\
\text { conduit }\end{array}$ & 42.9 & 30.3 & 46.4 & 39.3 \\
\hline $\begin{array}{l}\text { Middle } \\
\text { conduit }\end{array}$ & 16.7 & 13.5 & 15.7 & 14.3 \\
\hline Outlet & 18.2 & & & 12.4 \\
\hline
\end{tabular}

Figures 


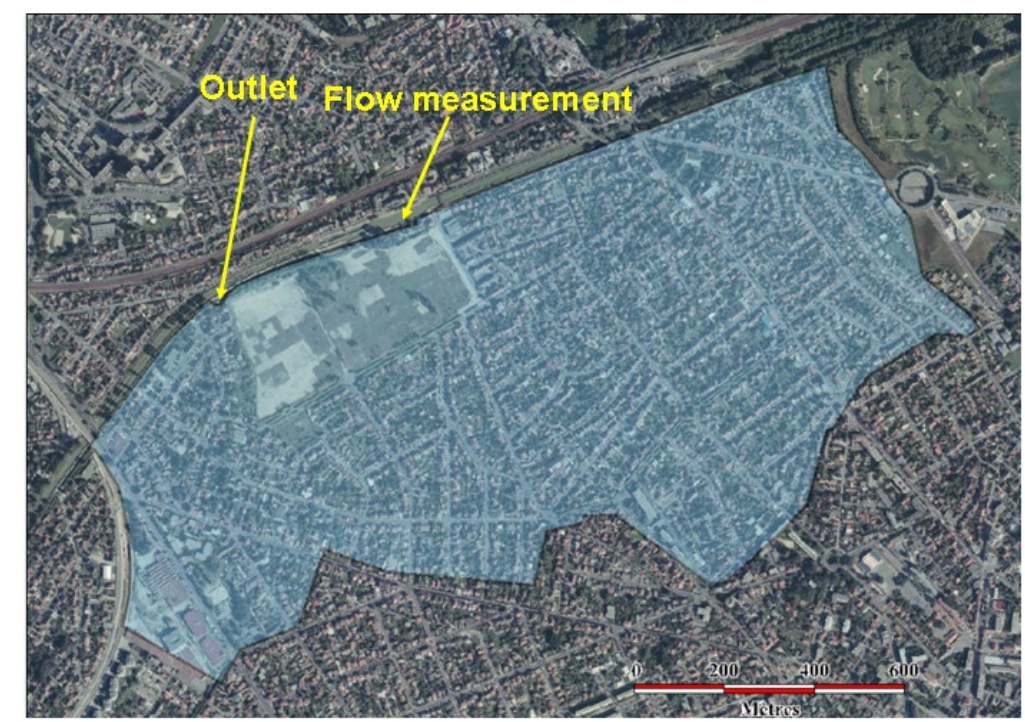

Figure 1: Picture of the 144 ha Kodak catchment, located in the city of Sevran (NorthEast of Paris)
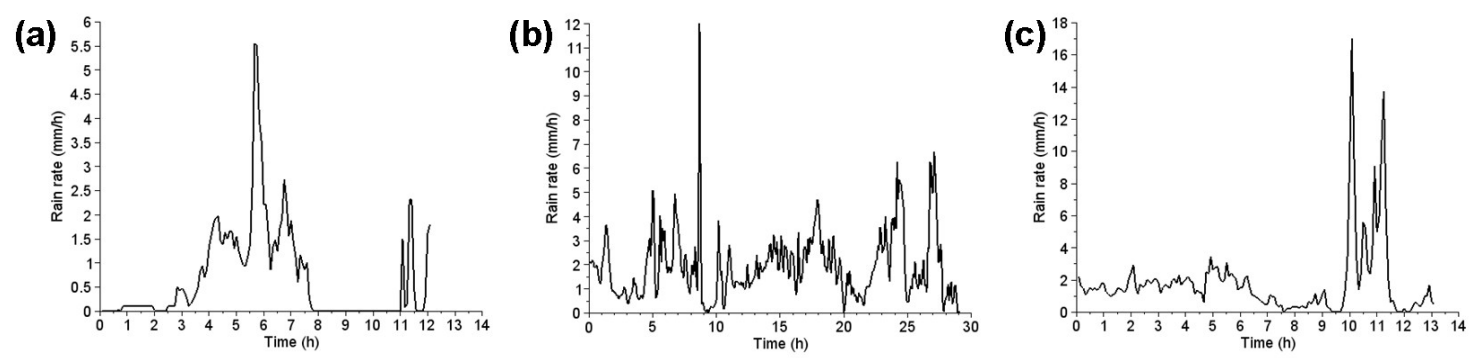

Figure 2: Temporal evolution of the average rain rate over the Kodak catchment measured by the radar for the selected events: (a) February 9 $9^{\text {th }}, 2009$; (b) August $15^{\text {th }}$ 2010; (c) December 15 ${ }^{\text {th }}, 2011$ 

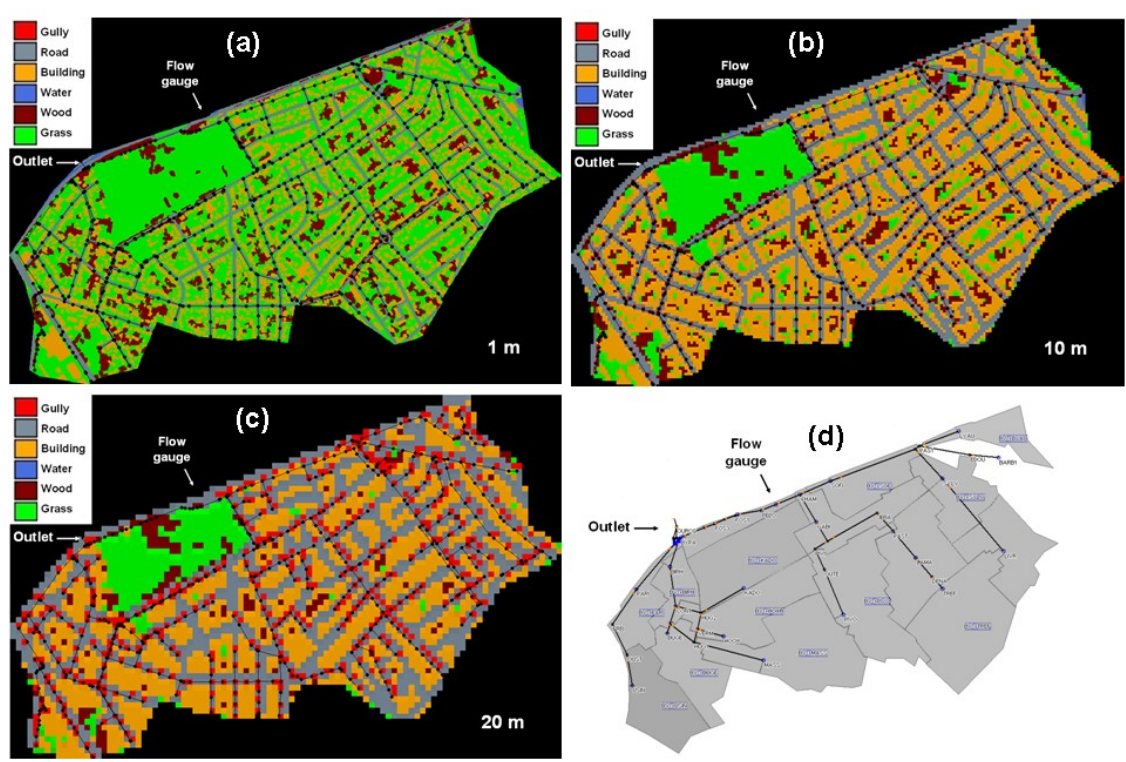

Figure 3: (a) Map of the land use distribution inputted in Multi-Hydro for the Kodak catchment with pixels of size $1 \mathrm{~m} \times 1 \mathrm{~m}$. The sewer network modelled with SWMM is superposed to this map (the nodes and conduits are visible along most of the roads). (b) As is (a) with pixels of size $10 \mathrm{~m}$ x $10 \mathrm{~m}$. (c) As is (a) with pixels of size $20 \mathrm{~m}$ x $20 \mathrm{~m}$. (d) Snapshot of the representation of this area with the 1D model Canoe. The subcatchments and the modelled sewer network are visible.

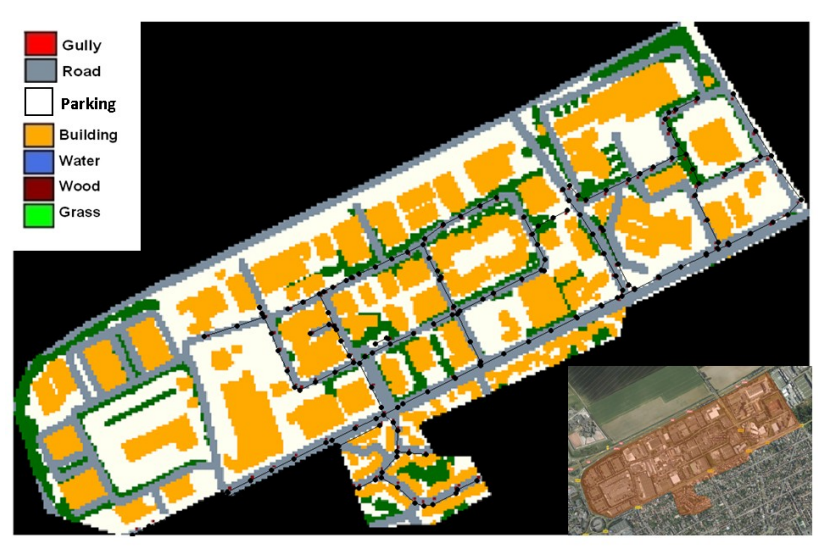

Figure 4: Map of the land use distribution inputted in Multi-Hydro for the Loup catchment with pixels of size $10 \mathrm{~m}$ x $10 \mathrm{~m}$. The sewer network modelled with SWMM is superposed to this map (the nodes and conduits are visible along most of the roads). Satellite image the catchment (lower right) 


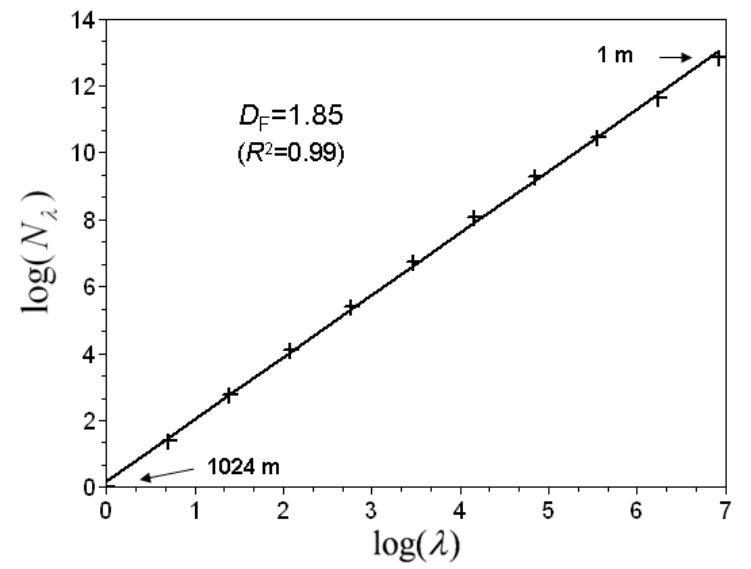

Figure 5: Estimation of the fractal dimension (Eq. 2 in a log-log plot) of the impervious portion of the Kodak catchment.

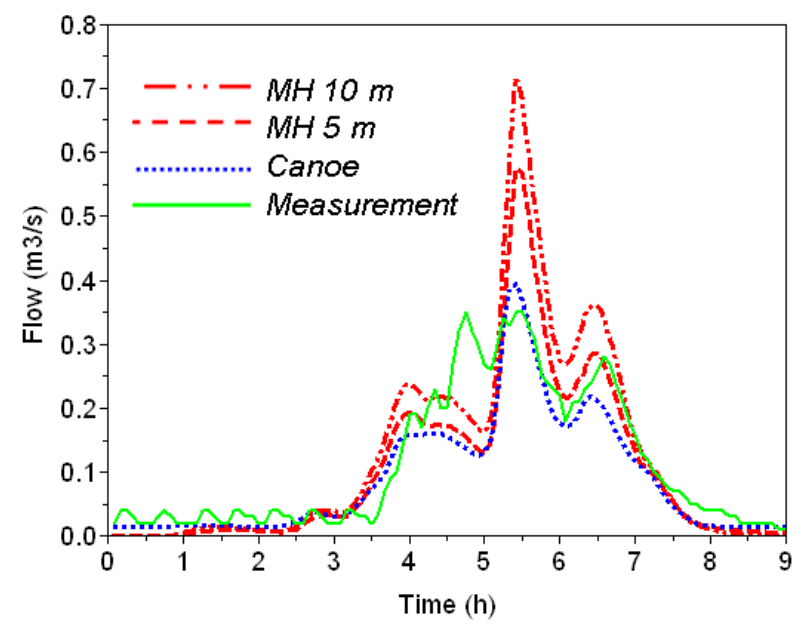

Figure 6: Comparison of measured flow and the simulated one by the different models for the Kodak catchment (see Fig. 1 for the location of the flow gauge where roughly $2 / 3$ of runoff water of the catchment is routed) 


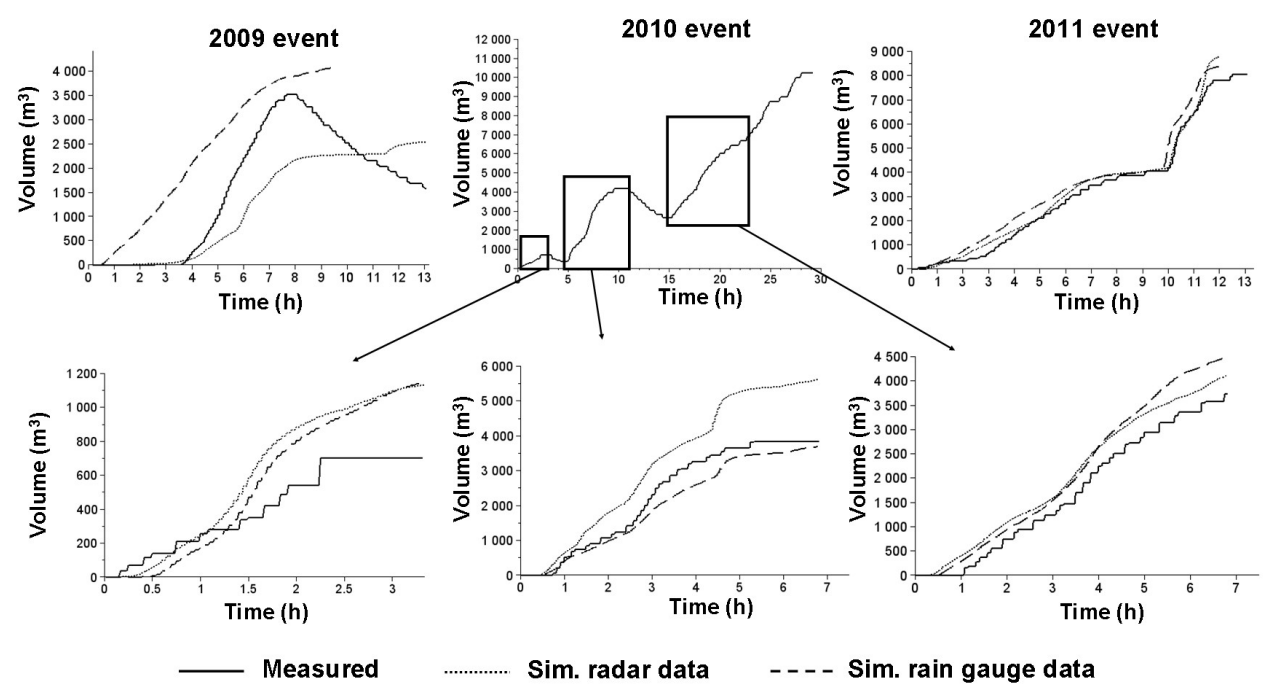

Figure 7: Comparison of the cumulated flow simulated with Multi-Hydro and observed for the Loup catchment.

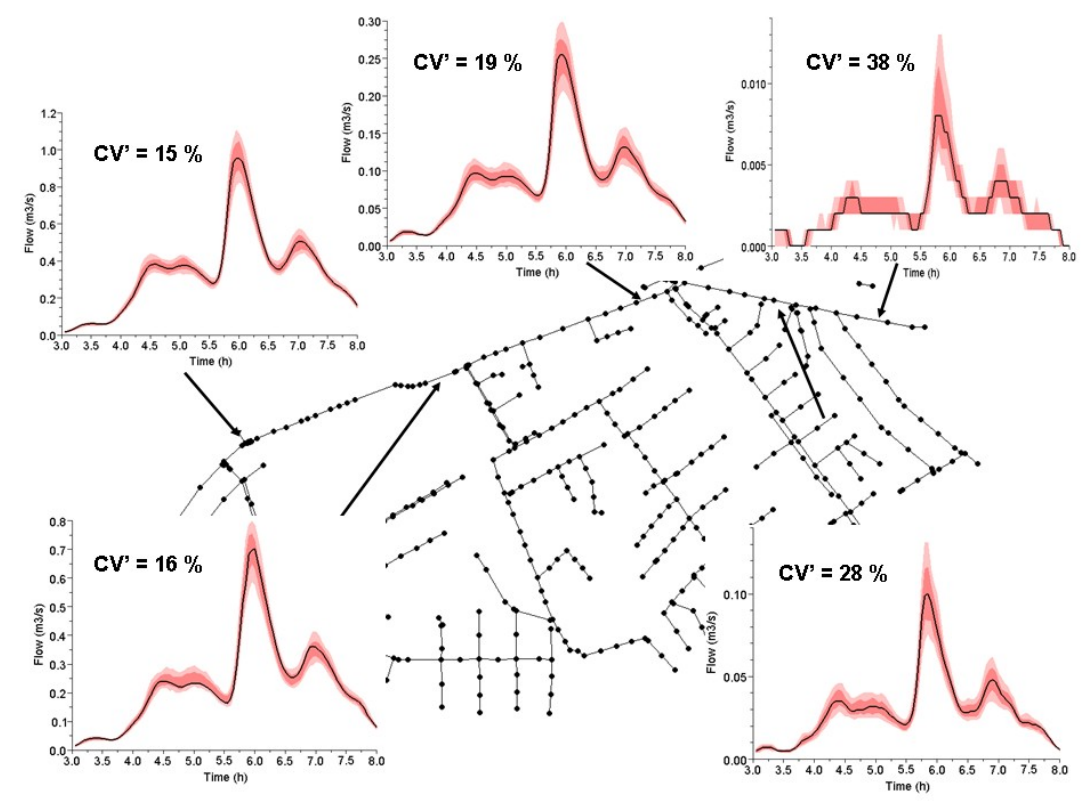

Figure 8: Simulated flow with the raw radar data (black), $Q_{0.25}$ and $Q_{0.75}$ (dark colour), $Q_{0.1}$ and $Q_{0.9}$ (light colour) for 5 conduits of the Kodak catchment with the help of the Multi-Hydro 10 m model for the 2009 rainfall event. 
(a)

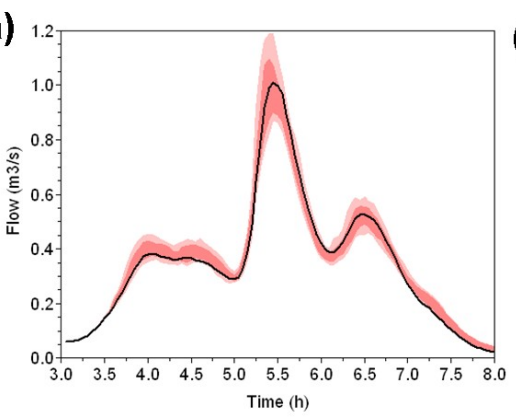

(c)

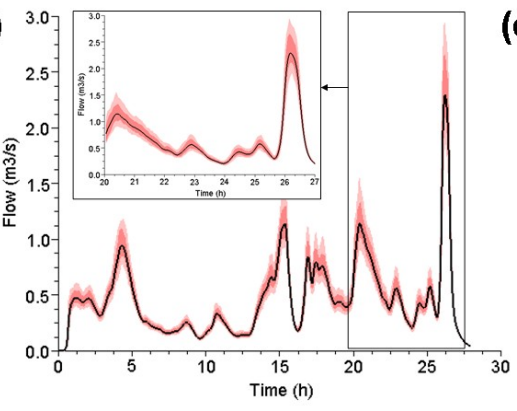

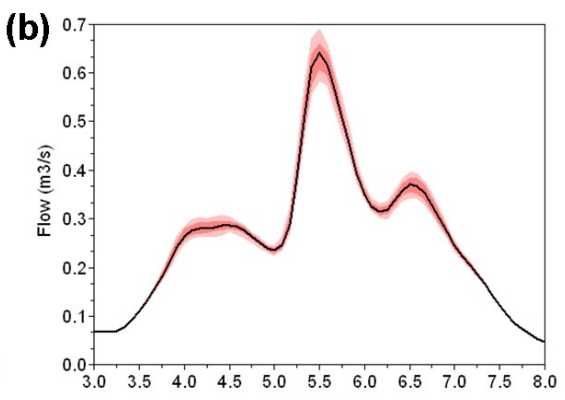

(d)

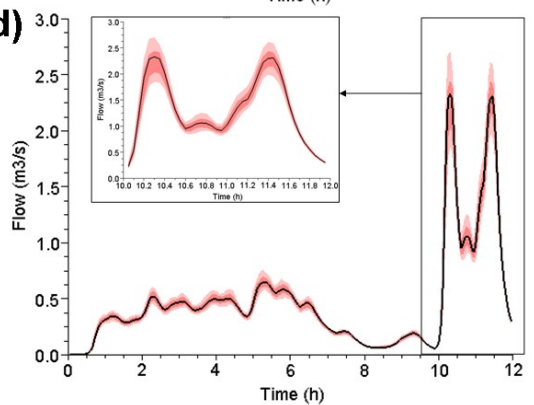

Figure 9: Simulated flow with the raw radar data (black), $Q_{0.25}$ and $Q_{0.75}$ (dark colour), $Q_{0.1}$ and $Q_{0.9}$ (light colour) for the outlet of the Kodak catchment. (a) Multi-Hydro $10 \mathrm{~m}$, 2009 event; (b) 1D model, 2009 event; (c) Multi-Hydro 10 m, 2010 event; (d) MultiHydro 10 m, 2011 event; 